\title{
Gender Violence and the Price of Virginity: Theory and Evidence of Incomplete Marriage Contracts
}

\author{
Daniel L. Chen*
}

\begin{abstract}
This paper builds and tests a model of marriage as an incomplete contract that arises from asymmetric virginity premiums and examines whether this can lead to social inefficiencies. Contrary to the efficient households hypothesis, women cannot prevent being appropriated by men once they enter marriage if they command lower marriage market opportunities upon divorce. Because men cannot or do not commit to compensating women for their lower ex post marriage market opportunities, marriage is an incomplete contract. Men may seek to lower women's ex ante "market wages" in order to induce entry into joint production. Inefficient or abusive marriages are less likely to separate. Equalizing virginity premiums may reduce domestic and nondomestic violence.

Female circumcision and prices women pay doctors to appear virgin before marriage in many countries suggest asymmetric virginity premiums continue to exist. Evidence from China and the US suggest asymmetric virginity premiums persist over economic development. Asymmetric virginity premiums are strongly positively correlated with female but not male virginity premiums. I use variation in religious upbringing to help estimate the effect of virginity premiums on gender violence in the US. The OLS relationship between virginity premiums and female reports of forced sex may be biased downwards if shame is associated with abuse and this shame is greater for women with higher virginity premiums. But the OLS relationship for males might not be biased downwards. Asymmetric virginity premiums are positively correlated with men forcing sex on women and paying women for sex. The model complements a growing empirical literature on inefficient households and human rights abuses, visible manifestations of female appropriability across time and space.
\end{abstract}

\footnotetext{
${ }^{*}$ Toulouse School of Economics, Institute for Advanced Study in Toulouse, University of Toulouse Capitole, Toulouse, France. daniel.chen@iast.fr. Most recent version at: http://users.nber.org/ d dlchen/papers/Gender_Violence_and_the_Price_of_Virginity.pdf. I thank colleagues and seminar participants at the University of Chicago, Northeast Universities Development Conference, Religion, Economics and Culture Conference, and Social Science History Association for helpful discussions, especially Abhijit Banerjee, Gary Becker, Esther Duo, Haluk Ergin, Chris Hansen, Sriya Iyer, Seema Jayachandran, Shareen Joshi, Michael Kremer, Steve Levitt, Imran Rasul, Chris Rohlfs, Jesse Shapiro, Adam Szeidl, Jeremy Tobacman, and Zaki Wahhaj, and the National Institute for Child Health and Human Development and National Science Foundation for financial support.
} 


\section{Introduction}

Gender violence is a human rights issue and a public health problem (IPPF). ${ }^{1} 40 \%$ of Chinese women experience unwanted sex or sex acts (Kew 2004). 25\% of young South African women's first sexual experience was forced (Epstein 2004). In the US, roughly one in five girls experience physical or sexual dating violence (Silverman 2001). Domestic violence is the leading cause of injury to women in the US and claims an estimated 4 million victims each year. Between one-third to one-half of all women are assaulted by a spouse or partner at some point during their lifetime. One-third of all female homicide victims are killed by a husband or boyfriend. The American Medical Association estimates the cost of domestic violence to be between \$5-10 billion per year (Rhode 1999).

Asymmetric virginity premiums are a metaphor for any inequality between men and women's ex ante and ex post marriage market opportunities. This includes stigma for divorced women but not for divorced men (Onishi 2003, Holden and Smock 1991, Bernheim et. al 2004, Joshi 2004), differential valuation placed on the number of partners (Connolly 2003), the conceptualization of virginity as a female virtue (Duby and Perrot, eds. 1994, Epstein 1973), penalty for lost labor market time (Hotchkiss and Pitts 2003, Crittenden 2001), child burden and marriage bars, and even differential STD transmission rates (Holmes 1999). The asymmetry appears to exist across time and space. A rich historical literature documents its existence (Duby and Perrot, eds. 1994) and imprint on legal and religious codes (Epstein 1973). The asymmetry still exists today: approximately 2 million girls a year encounter female genital mutilation (Nussbaum 1996), under the belief it guarantees a girl's virginity. In many countries, women seek surgery to restore virginity ñand in a report in the British medical journal, The Lancet, the availability of the surgery reduced by $80 \%$ the murders committed when a bride was found not to be a virgin (Kandela 1996).

Is there a connection between asymmetric virginity premiums and gender violence? To theoretically explore the connection, I build a model of marriage as an incomplete contract where men and women differ in ex ante and ex post marriage market opportunities. The difference-in-differences is termed the asymmetric virginity premium. The model predicts that wives or their families should be compensated ex ante for loss of virginity, such as courtship rituals, lower dowries, or higher bride prices. It also predicts that as long as

\footnotetext{
${ }^{1}$ Whether it takes the form of psychological, physical, or sexual abuse, gender violence has been linked to increased risk of gynecological disorders, unsafe abortion, pregnancy complications, miscarriage, low birth weight, pelvic inflammatory disease, and H.I.V. (IPPF).
} 
marriage has a positive surplus, men have the incentive to lower women's ex ante market wages to encourage entry into joint production (non-domestic assault). Marriages revealing negative surpluses after marriage would separate under complete contracts but do not under asymmetry (domestic assault). Equalizing virginity premiums therefore may reduce non-domestic and domestic violence.

To empirically examine whether asymmetric virginity premiums lead to gender violence, I analyze two data sets, the Chinese Health and Family Life Survey (CHFLS) and National Health and Social Life Survey (NHSLS), nationally representative surveys of China and the US, consisting of 3,821 and 3,432 adults respectively, where I infer virginity premiums from self-reported morality of premarital sex. I first document that asymmetric virginity premiums persist in China and the US. To motivate computing individualized asymmetric virginity premiums, I find that in China but not the US, the asymmetry disappears with education, and in the US, the asymmetry is highest in the US South.

I then estimate an individualized asymmetric virginity premium by calculating the virginity premium if an individual's gender were switched, in essence, matching an individual to the closest person of the opposite gender based on observed characteristics, such as education and location.

The OLS relationship between asymmetric virginity premiums and female reports of forced sex may be biased downwards if shame is associated with abuse and this shame is greater for women with higher virginity premiums (French 2003). "Blaming the victim" (Rubinger, et. al) may be prevalent in male-centric societies that lower the marginal cost to males of manipulating female market wages. To address this non-classical measurement error, I first observe that asymmetric virginity premiums are strongly positively correlated with female premiums but not male premiums, which theory predicts if male premiums go to zero and female premiums do not. This suggests that examining the impact of female virginity premiums alone may be similar to examining the impact of asymmetric virginity premiums, necessary because any instrumental variables strategy involving demographic variables would be mechanically related to the asymmetry, which is computed using these demographics. I then use variation in conservatism of religious upbringing to help identify the effect of female virginity premiums on gender violence.

In the US, female virginity premiums are strongly linked with religious conservatism. Women raised in religiously conservative households have higher virginity premiums and suffer more forced sex, but are no more likely to refrain from thinking about sex or think of teenage sex as a moral issue, indicating that premiums are not capturing prudishness or 
general moral views towards sex. I also conduct a series of control experiments, alternatively examining women raised in less educated or immigrant households, to test whether traditionalism may be an omitted confound that explains the link between virginity premiums and gender violence.

The OLS relationship between asymmetric virginity premiums and male reports of forced sex might not be biased downwards. In fact, asymmetric virginity premiums are positively correlated with men forcing sex on women and paying women for sex.

Economists have traditionally built models of households as being efficient (Becker 1991, Chiappori and Weiss 2003), but a growing empirical literature suggests they are not (Duflo and Udry 2003, Qian 2004). This paper presents a theory showing why households might not be efficient. It is also related to a growing literature on gender violence (Stevenson and Wolfers 2003, Bowlus and Seitz 2002, Bloch and Rao 2002, Pezzini 2003, Aizer and Bo 2004), marriage and contract theory (Chiappori and Weiss 2003, Rasul 2004), and impact of beliefs (Chen 2004b).

Section 2 presents qualitative evidence of asymmetric virginity premiums from historical and contemporary records. Section 3 constructs a model showing how, contrary to the efficient households hypothesis, women cannot prevent being appropriated by men once they enter marriage if they command lower marriage market opportunities if divorced. Section 4 presents quantitative evidence of asymmetric virginity premiums in China and the US. Section 5 presents two-stage least squares estimates of the impact of virginity premiums on forced sex using variation in virginity premiums that stems from religious upbringing in the US. Section 6 concludes.

\section{Qualitative Evidence of Asymmetric Virginity Premiums}

In antiquity, virginity appears to have been typically an exclusively female virtue. It was inculcated as the supreme value for all women. Christianity justified that value based on theology: virgins could expect greater rewards in heaven than married women. Not only the fate of the child's soul but the honor of the family depended on it. Stained linen from the marriage bed was often the sole admissible proof of a bride's virginity. Slave girls whose virginity could be proven sold for higher prices. On the other hand, puberty and sexual initiation were synonymous for boys. (Duby and Perrot, eds. 1994)

Legal and religious codes also give evidence of asymmetric virginity premiums. Divorced women, widows, and unwed mothers were ineligible for part of the bride price 
that was conceived as "the price of virginity". Rabbinic law prescribed a fine equal to a minimum mohar (bride price of 50 shekels) of virgins for rape (Deuteronomy 22:29) and seduction (Exodus 22:15-16), which represented theft of virginity (Epstein 1973). Rape and consensual nonmarital sex are still equated in parts of Turkey today (Filkins 2003).

Asymmetric virginity premiums continue to exist around the world, however. Approximately two million girls a year encounter female genital mutilation (Nussbaum 1996), because circumcision is believed to guarantee a girl's virginity, thus make them marriageable. In Arabic, uncircumcised girls are considered filthy and unclean. Girls are taught that their most important mission in life is to remain virgins until they marry. If they don't, there are cases where fathers kill their daughters or send them to asylums (such as the Magdalene Asylums in Ireland). "In Yemen recently, a man shot his daughter dead on her wedding night after her husband said she was not a virgin. ... A father learned his daughter had eloped with a man. Gathering sons, brothers, uncles and cousins, he headed north in a convoy of about 20 cars. The men stormed the bride's new home and threw her into one of the cars. When the convoy reached the edge of her village, her father hurled her to the asphalt and had every car drive over her." (Seattle Times 1998)

In many countries, women seek surgery to restore virginity. The surgery typically involves suturing the remnants of the ruptured hymen together with a gelatin capsule containing a bloodlike substance (Choi 1998). These surgeries are found in China, Korea, Indonesia, Egypt, Jordan, Turkey, Morocco, and even the Netherlands, New York City, and Los Angeles (Pan 2003). This creolization of modern medical technology and traditional social mores is not limited to Islamic and Asian countries: "virginity soap" is sold all over eastern and southern Africa (Oriang 2003). Police report the availability of the surgery in Egypt reduced by $80 \%$ the murders committed when a bride was found not to be a virgin on the wedding night (Kandela 1996). Prices for the surgery vary from $\$ 340$ in China, $\$ 100-600$ in Egypt, and an average of $\$ 570$ in Turkey (Choi 1998).

Even the US, where several states have abstinence-only sex education, use language that differentially faults women: "Go ahead and use a condom. You'll still be known as a slut" (Connolly 2003). In a sample of a faith-based community, $14 \%$ believe if women submit to their husbands as God desires there would be less spouse abuse, $9 \%$ believe if a woman submits to her husband as God desires, God will give her the strength to endure the abuse, and $10 \%$ believe as a Christian, they should be willing to accept a marriage in which some violence is present, rather than separate or divorce (Drumm, et.al 2004).

A recent interview in the Chicago Tribune Magazine (Schleffer 2004) illustrates different 
aspects of the model and empirical work. It suggests the phenomena might be attenuated in the US but if we do find an effect here, the asymmetry and its effects could be much worse in developing countries.

"For Carolina, 35, a first-generation Puerto Rican interviewed for this story, coming of sexual age involved a formal courtship that placed a premium on keeping her and her sisters in check (emphasis added). In her household, boys would come to the house and "declare" themselves; that is, they would tell the parents that they wanted to date their daughters. Ground rules would be set: Boys were allowed to visit on Tuesdays and Saturdays.

"My sisters never dated," says Carolina, the youngest in a family of 12 . "The first guy who declared himself is the guy they married. The American way, where you date different people and see who you like, wasn't an option."

Carolina and her sisters would meet boys at socially sanctioned and closely monitored places, such as church and family gatherings, not at high school.

The rules did not apply for the males in the family. Carolina says her father was something of a womanizer in Puerto Rico, and her brothers, once they moved to the U.S., were allowed to date whomever they wanted, all the while keeping a close eye on their sisters.

One reason for the restrictions is the fear of pregnancy among traditionally devout Catholic Puerto Rican families, for whom birth control and abortion are not up for discussion.

Even when it came time to go off to college, Carolina's mother was against it. "She said: 'A girl doesn't study, a girl gets married. You're going there with all those 'Americanos.' In my mothers book, they were the unknowns," says Carolina. " 'All you want to do is go have sex with boys,' she'd tell me."

But the sexual guilt hasn't necessarily gone away. Since she's not married, it's assumed among certain family members in her community that she still has her virginity. "That's how prized it [is] to this very day," she says."

The asymmetric virginity premium is a metaphor for any inequality between men and women's ex ante and ex post marriage opportunities. In Bangladesh, widows have lower re-marriage rates than widowers (Joshi 2004). In South Korea, divorced women are stigmatized as promiscuous or heavy drinkers (Onishi 2003). Today's lost labor market time and child burden may substitute for yesterday's price of virginity. Divorced men are better off than divorced women (Holden and Smock 1991, Bernheim et.al 2004). A sizeable wage penalty exists for intermittency (Hotchkiss and Pitts 2003) and women are doubly penal- 
ized for their lost labor market time (Crittenden 2001) or disallowed from working after entering marriage (historical Japan, US, and Indonesia). Depending on the social mores, marriage itself can be a metaphor for dating and social stigma appears to rise for women with many sexual partners but not for men. Even in the US, asymmetric virginity premiums seem to persist: a Manhattan defendant who raped a retarded woman got a reduced sentence because she had been raped before and the court assumed that the impact of the assault was therefore "considerably less" severe (Rhode 1999).

\section{Model}

The starting point for the analysis is a very simple model. Let $w_{m a}$ denote male ex ante wages, $w_{f a}$ denote female ex ante wages, $w_{m p}$ denote male ex post wages, and $w_{f p}$ denote female ex post wages, where $w_{f a}-w_{f p}>w_{m a}-w_{m p}$, which indicates a greater female virginity premium, $w_{f a}-w_{f p}$, than male virginity premium, $w_{m a}-w_{m p}$.

To illustrate the basic intuition, consider the extreme case where women receive nothing ex post and men have exactly the same ex ante and ex post opportunities: let $w_{f p}=0$, $w_{m a}=w_{m p} \equiv w_{m}$, and $w_{f a} \equiv w_{f}$. Suppose $J$ is the joint surplus in marriage and is divided under Nash bargaining. Under standard bargaining theory, agents receive their outside opportunity plus a share of joint production. Females receive $S / 2$ and males receive $S / 2+w_{m}$, where $S+w_{m}=J$.

If the joint surplus is not sufficiently large ${ }^{2}$, females suffer a drop from $w_{f}$ to $\left[J-w_{m}\right] / 2$ but males gain from $w_{m}$ to $w_{m}+\left[J-w_{m}\right] / 2$. Because of the asymmetry, men have the incentive to compensate women or their families ex ante for virginity: men are willing to transfer up to $\left[J-w_{m}\right] / 2$, their private gain from joint production, to encourage women to enter joint production. Men also have the incentive to lower women's ex ante market wages until women are indifferent between autarky and joint production.

Now suppose $J$ is uncertain and the surplus can be revealed to be negative after marriage. Under complete contracts, where there are no virginity premiums and everyone has the same ex ante and ex post market wages, if the realized marriage surplus is negative, marriages will efficiently separate. But they will not under asymmetry.

To show these propositions rigorously, consider the more general formulation where $w_{f a}-w_{f p}>w_{m a}-w_{m p}$, where we only assume a greater female premium than male

\footnotetext{
${ }^{2}$ and not too small, $w_{m}<J<2 w_{f}+w_{m}$
} 
premium. Females receive $S / 2+w_{f p}$ and males receive $S / 2+w_{m p}$, where $S+w_{m p}+w_{f p}=J$. Females suffer a drop from $w_{f a}$ to $\left[J-w_{m p}+w_{f p}\right] / 2$ if joint production is too small $\left(J<2 w_{f a}+w_{m p}-w_{f p} \equiv J_{\max }\right)$. Males gain from $w_{m a}$ to $\left[J+w_{m p}-w_{f p}\right] / 2$ if joint production exceeds a threshold $\left(J>2 w_{m a}-w_{m p}+w_{f p} \equiv J_{\min }\right)$. There exists a range of $J$ such that men gain more from joint production than do women, and the range is twice the differential virginity premium: $J_{\max }-J_{\min }=2\left[\left(w_{f a}-w_{f p}\right)-\left(w_{m a}-w_{m p}\right)\right]$.

Algebraically, the change in female welfare is $\left[J-w_{m p}+w_{f p}\right] / 2-w_{f a}$; the change in male welfare is $\left[J+w_{m p}-w_{f p}\right] / 2-w_{m a}$. Males gain more when $\left[J+w_{m p}-w_{f p}\right] / 2-w_{m a}-$ $\left[J-w_{m p}+w_{f p}\right] / 2+w_{f a}=\left[w_{m p}-w_{f p}\right] / 2-w_{m a}-\left[-w_{m p}+w_{f p}\right] / 2+w_{f a}=\left(w_{f a}-w_{f p}\right)-$ $\left(w_{m a}-w_{m p}\right)$, which is the asymmetric virginity premium. The change in female welfare is negative when $\left[J-w_{m p}+w_{f p}\right] / 2-w_{f a}<0$, or equivalently, $J<2 w_{f a}+w_{m p}-w_{f p} \equiv J_{\max }$. The change in male welfare is positive when $\left[J+w_{m p}-w_{f p}\right] / 2-w_{m a}>0$, or equivalently, $J>2 w_{m a}-w_{m p}+w_{f p} \equiv J_{\min }$.

This leads to the first proposition:

Proposition 1 : Wives or their families should be compensated ex ante for loss of virginity, such as courtship rituals, lower dowries, or higher bride prices. The greater likelihood the woman is a virgin, the greater the bride price or smaller the dowry. Positive shocks to virginity premiums increase bride prices and decrease dowries.

Suppose males can compensate females ex ante with any transfer $T>0$. Males are willing to transfer up to $\left[J+w_{m p}-w_{f p}\right] / 2-w_{m a}$, their private gain from joint production. The transfer must be large enough to compensate females for their prospective loss: $T+$ $\left[J-w_{m p}+w_{f p}\right] / 2-w_{f a}>0$. Males will set $T=w_{f a}-\left[J-w_{m p}+w_{f p}\right] / 2$ to make females indifferent between joint production and autarky, if they have the resources. Males have the resources when their willingness to transfer $\left[J+w_{m p}-w_{f p}\right] / 2-w_{m a}$, exceeds the woman's loss $w_{f a}-\left[J-w_{m p}+w_{f p}\right] / 2$, or equivalently, $J>w_{m a}+w_{f a} \equiv J_{m i d}$. There exists a range of $J$ such that ex ante transfers are enough to compensate for the woman's loss of virginity: $J_{\max }>J_{\text {mid }}>J_{\min } ; J_{\text {mid }}$ is the average of $J_{\min }$ and $J_{\max }$. As the likelihood of virginity, $w_{f a}$, rises or the premium, $w_{f a}-w_{f p}$, rises, $T$ tends to rise as well.

Time between menarche and age of marriage is positively associated with the dowry paid by the woman's family to the man's family (Bangladesh, Field 2004), one interpretation of which is that the lower the likelihood the woman is virgin, the greater the dowry. In some societies (rabbinic law), bride prices literally translated into, the price of virginity, paid at the time of a woman's first marriage but not for subsequent ones. That bride prices are 
paid to a woman's family prevents immediate appropriation by the man in marriage. In Roman law, dowries were restituted to women if they had not lost their virginity when the marriage was dissolved. Other forms of transfers include gifts of cash or consumer goods from boyfriends (southern Africa) and, more generally, marriage promises and unidirectional presents (betrothal present) as courtship ritual (Epstein 1973).

There exists a range of surpluses $J_{\text {mid }}>J>J_{\text {min }}$, where ex ante transfers are not enough to compensate for the woman's loss. Then, the second observation is:

Proposition 2 : Men have the incentive to lower women's ex ante market wages, $w_{f a}$, in order to induce entry into joint production. Male-centric societies tend to lower the marginal cost of ex ante manipulation.

If males reduce female ex ante wages to below what they receive in marriage, females will prefer joint production. In the absence of transfers, males will reduce female ex ante wages, $w_{f a}$, until females are indifferent: $w_{f a}=\left[J-w_{m p}+w_{f p}\right] / 2 \equiv w_{f}^{\text {indiff }}$. With transfers, males will set ex ante transfers, $T$, and ex ante manipulation, $w_{f a}$, until women are indifferent between autarky and joint production, $T+\left[J-w_{m p}+w_{f p}\right] / 2-w_{f a}=0$. In rabbinic law, unwed mothers who have lost their virginity cannot claim part of the brideprice (Epstein 1973). Shotgun marriages is one manifestation of ex ante manipulation. As recently as the mid-20th century, women were required to marry once they become pregnant (Bernstein 2004). In Islam, men who take a woman's virginity are required by law to marry them. Some betrothed couples used pregnancy to obtain parental consent (Duby and Perrot, eds. 1994).

Men will equate the marginal cost of transfers $C^{\prime}(T)$ to the marginal cost of manipulation $C^{\prime}\left(w_{f a}\right)$. A social planner can raise the marginal cost of ex ante manipulation, $C^{\prime}\left(w_{f a}\right)$, but male-centric societies that only consider male welfare will tend to lower the marginal cost of ex ante manipulation, hence the phenomenon of "blaming the victim", again common around the world. Brazilian police often subject domestic violence victims to abusive treatment aimed at implicating her in the crime (Rubinger, et.al). In Japan, victims of rape are typically blamed (French 2003). This happens in China and Pakistan too: abandonment of rape victims for the "shame they inflict" on relatives (Kahn and Yardley 2004) and the expectation that they commit suicide (Kristof 2004). Women are told if you suffer molestation or groping, you should be ashamed. Talking about it to anyone taints you for the rest of your life. Recently a member of the Japanese Parliament said boys who commit group rape are in good shape and that they are rather normal. (French 2003) 
Ex ante manipulation may entail negative externalities, which leads to the third observation:

Proposition 3 : Equalizing virginity premiums, prenuptial agreements, and alimony rights - any mechanism that reduces the asymmetry - reduce the incentive for men to manipulate women's ex ante market wages.

Lowering female virginity premiums (by raising $w_{f p}$ ) or raising male virginity premiums (lowering $w_{m p}$ ) raise $w_{f}^{\text {indiff }} \equiv\left[J-w_{m p}+w_{f p}\right] / 2$. The higher is $w_{f}^{\text {indiff }}$, males have less incentive to reduce $w_{f a}$. In the case of equal virginity premiums, $J_{\max }=J_{\min }$, there is no range of $J$ where asymmetric gains from joint production incentivize ex ante manipulation. Intuitively, both men and women become specified to the marriage. Equalizing virginity premiums completes the incomplete marriage contract.

Now suppose the marriage production $J$ is uncertain and the surplus, $S \equiv J-w_{m p}-w_{f p}$, can be revealed to be negative in marriage. Studies of abused women in the US have shown that the majority do not experience physical violence until after they marry. After they marry, the frequency and severity of violence tends to escalate (Heise, et.al 1994).

Proposition 4 : Asymmetry increases the incidence of abusive marriages. There exists a range of marriages with negative surpluses $S$, which would have efficiently separated under complete contracts but do not separate under asymmetric virginity premiums.

Under complete contracts, where there are no virginity premiums and everyone has the same ex ante and ex post market wages, if the realized marriage surplus is negative, $J<J_{\min }$, then marriage does not guarantee agents' outside opportunities, marriages will efficiently separate.

Under asymmetric virginity premiums, women are less inclined to separate. But men are also less inclined to separate. Women still need to be sufficiently compensated for their appropriation. Men's ex post market wages may be lowered until their threat point is sufficiently low. Recall that females receive $S / 2+w_{f p}$ and males receive $S / 2+w_{m p}$, where $S+w_{m p}+w_{f p}=J:$ as $w_{m p}$ falls, females receive a larger share $\left[J-w_{m p}+w_{f p}\right] / 2$. To sufficiently compensate the woman, $w_{m p}$ falls to $w_{m p}^{\prime}$ such that $T+\left[J-w_{m p}^{\prime}+w_{f p}\right] / 2-w_{f a}=$ 0 , in other words, $w_{m p}^{\prime}=J-2\left(w_{f a}-T\right)+w_{f p}$. As the female premium rises, $w_{f p}$ falls or $w_{f a}$ increases, $w_{m p}^{\prime}$ falls as well.

Hence, not only is the woman's incentive to separate an inefficient marriage lower, but the man's incentive to separate is also lower. Marriages that should separate may not 
under asymmetric virginity premiums. Studies of divorced or widowed men suggest partial appropriation of the man to marriage (Waite). More formally, to show there exists a range of negative surplus marriages which do not separate under asymmetric virginity premiums: holding fixed what women receive in marriage ${ }^{3}$, the lower are women's outside options $w_{f p}$, the less likely they choose to separate. Women receive $S / 2+w_{f p}$ inside marriage and if $S<0$, then clearly women separate and receive $w_{f p}$ outside. But if what women receive

outside marriage falls $\left(w_{f p}^{\prime}<w_{f p}\right)$, then marriages only separate when $S<2\left[w_{f p}^{\prime}-w_{f p}\right]$. In the extreme case, women are killed attempting to file for divorce, as happened recently in Pakistan (Lakhani 2004). Similarly, depressing male's outside options lead to marriages only separating when $S<2\left[w_{m p}^{\prime}-w_{m p}\right]$.

Asymmetric virginity premiums lead to welfare losses and social inefficiencies as factors in joint production do not separate even as their joint surplus becomes negative. Equalizing virginity premiums can be Pareto improving.

\section{$3.1 \quad$ Summary}

To summarize, the model has the following empirical predictions.

- Asymmetric virginity premiums increase the incentive for men to lower women's ex ante market wages (non-domestic assault).

- Asymmetry increases the incidence of abusive marriages (domestic assault).

\section{Asymmetric Virginity Premiums in China and the US}

\subsection{Data}

The empirical analysis draws from the Chinese Health and Family Life Survey (CHFLS) and the (US) National Health and Social Life Survey (NHSLS). CHFLS is a nationally representative survey conducted between 1999 and 2000 of the adult population in China, ages 20 to 64, with the exception of Tibet and Hong Kong. Interviewers were the same gender as the respondent. For the sake of privacy, interviews took place away from the respondent's home. Portions of the interview were completely computerized to maximize privacy. The sample size is 3,821 . The NHSLS is a nationally representative survey of

\footnotetext{
${ }^{3}$ If what women receive in marriage is not fixed, the lower are women's outside options $w_{f p}$, the lower is her share $\left[J-w_{m p}+w_{f p}\right] / 2$ of the surplus, which suggests a direct relationship with domestic abuse.
} 
the US adult population in 1992 with a sample size of 3,432. Portions of the interview were answered and submitted in a privacy envelope away from the interviewer to maximize privacy.

In CHFLS, the measure of virginity premiums refers to the question, "Nowadays in our society, some couples have sex when they are dating, and they eventually get married. Is this a moral issue? What is your opinion? Definitely not (1)/mostly not/perhaps yes/definitely yes (4)" The question is coded as $1 / 2 / 3 / 4$, with higher values indicating increasing moral value placed on virginity. To check whether this question proxies for traditionalism, I compare responses to the question, "Some say that a wife should be responsible for the family and domestic tasks while a husband should focus on career and matters outside the household. Do you agree?" The question is also coded as $1 / 2 / 3 / 4$. The comparison highlights a premium placed on virginity not just traditional gender roles in general.

In NHSLS, the measure of virginity premiums refers to the question, "There's been a lot of discussion about the way morals and attitudes about sex are changing in this country. If a man and a woman have sex relations before marriage, do you think it is always wrong, almost always wrong, wrong only sometimes, or not wrong at all?" The question is coded as $1 / 2 / 3 / 4$, with higher values indicating increasing moral value placed on virginity. There are no questions regarding traditional gender roles so as comparison, I consider the question, "What if they are in their teens, say 14-16 years old? In that case, do you think sex relations before marriage are always wrong, almost always wrong, wrong only sometimes, or not wrong at all?" The question is also coded as $1 / 2 / 3 / 4$. This comparison highlights a particular premium placed on virginity as opposed to teenage sexual activity.

The analysis assumes respondents answer the morality of premarital sex question as referring more strongly to the behavior of themselves as opposed to others. Whether this is true relies on two thought experiments. One is to ask, do or did you prefer yourself/your spouse to be virgin at time of marriage, and examine whether the difference-in-differences in male and female responses correspond to the original question. Alternatively, one can imagine a second-price auction where bidders are randomly assigned information on virginity of potential marriage partners. The question is whether virginity as moral issue is more positively related to a male bidder's valuation of virginity and more positively related to a female biddee's valuation of virginity than they are to a female bidder's valuation and male biddee's valuation.

The female measure of gender violence refers to the question, "This section relates to 
what you have done sexually with a man since you reached puberty (that is since you were about 13 years old). Have you ever been forced by a man to do something that you did not want to do?" The question is coded as $1 / 0$. I show both linear probability and probit marginal effects specifications. Using self-reported forced sex addresses some of the concerns of human rights activists that pain may be culturally specific and social scientists ought not to define what is "forced" for others. A social planner would also optimize self-reported utility.

The male measure of gender violence refers to the question, "This section relates to what you have done sexually with a woman since you reached puberty (that is since you were about 13 years old). Have you ever forced a woman to do something that she did not want to do?" The question is coded as $1 / 0$. I also examine the question, "Have you ever paid a woman to have sex?"

\subsection{China}

Table 1 reports evidence of asymmetric virginity premiums in China. OLS estimates indicate females have higher virginity premiums than males, and this relationship is robust to controls:

$$
P_{i j}=\beta F_{i j}+\alpha^{\prime} \mathbf{X}_{i j}+\gamma_{j}+\varepsilon_{i j}
$$

where $P_{i j}$ represents the virginity premium for individual $i$ at interview site $j, F_{i j}$ is a dummy for whether the individual is female, $\mathbf{X}_{i j}$ represents demographic control variables, age, education, urban, working, income, living at home, and household size, and $\gamma_{j}$ represents interview site fixed effects.

The estimates indicate a strong association between the female dummy and virginity premiums that is very robust to control variables. The estimates 0.255 and 0.251 between Columns 1 and 2 are remarkably similar. Examining actual premarital sex behavior indicates a similar pattern in Columns 3 and 4 . Females are less likely to have premarital sex. To test for the possibility the measure of virginity premium merely captures traditional views on gender roles, I repeat the regression with a proxy for traditionalism in Columns 5 and 6 . Interestingly, females are no more likely to report valuing traditional gender roles than are males, suggesting there is something particular about virginity as opposed to general traditional values that females are concerned about.

Asymmetric virginity premiums (AVP) also vary systematically along certain demo- 
graphic characteristics. Table 2 shows how the asymmetry disappears with education. It reports OLS estimates of an interaction model relating virginity premiums and a female dummy interacted with demographic controls:

$$
P_{i j}=\beta_{0} F_{i j}+\beta_{1}^{\prime} \mathbf{X}_{i j} F_{i j}+\alpha^{\prime} \mathbf{X}_{i j}+\gamma_{j}+\varepsilon_{i j}
$$

Columns 1 and 2 indicate the asymmetry disappears with education (which varies from 1 to 6), which may explain why some places worry education corrupts a young lady's morals (Kristof 2004, Schleffer 2004) and why education may not be a panacea if girls' schools are burned (Constable 2003). Columns 3 and 4 indicate education does not play a role in reducing the asymmetry in actual premarital sex behavior. Columns 5 and 6 suggest that at low education levels, females value traditional gender roles more than do males but at high education levels, males value traditional gender roles more than do females.

\subsection{US}

Asymmetric virginity premiums appear to persist over economic development. Table 3 reports OLS estimates of the analog of Table 1:

$$
P_{i j}=\beta F_{i j}+\alpha^{\prime} \mathbf{X}_{i j}+\gamma_{j}+\varepsilon_{i j}
$$

where $P_{i j}$ represents the virginity premium for individual $i$ in region $j, F_{i j}$ is a dummy for whether the individual is female, $\mathbf{X}_{i j}$ represents demographic control variables, age, education, urban, income, white, immigrant, household size, and raised with religion, and $\gamma_{j}$ is region fixed effects.

The estimates again show a strong association between females and virginity premiums that is robust to demographic controls. The estimates 0.272 and 0.203 in Columns 1 and 2 are very similar. Perhaps interestingly, these estimates are also similar to the female gradient in China, 0.251 in Table 1 Column 1. Examining actual premarital sex behavior indicates a similar robustness in Columns 3 and 4 . Females are again less likely to have premarital sex. Columns 5 and 6 repeat the regression with the views on teenage sex. Females are again more concerned about teenage sex than are males. In the US, asymmetric virginity premiums do not decrease with education; the analog of Table 2 is not displayed.

Why asymmetric virginity premiums disappear with education in China but not the U.S. may be related to the role of religion in the U.S., where there tends to be a posi- 
tive correlation between religious attendance and years of education. In former socialist countries there is a negative relationship between years of education and belief in God, whereas in many developed countries, including the U.S., there were strong positive correlations between years of education and belief in God (Glaeser and Sacerdote 2008). If religious beliefs are a driver of asymmetric virginity premiums, this difference between the two countries would imply that the asymmetry can persist with education.

\subsection{Individualized Asymmetric Virginity Premiums}

Appendix Table B shows average female and male virginity premiums for the US East (New England and Mid-Atlantic), US West (Pacific), US South (East South Central, West South Central, and South Atlantic), and US Midwest (East North Central, West North Central, and Mountain) and their asymmetry. The second column indicates virginity premiums are highest in the US South and lowest in the US East. The asymmetry is also highest in the US South. The relationship between female virginity premiums and asymmetric virginity premiums is not mechanical: it could have been the case that as female premiums rise, male premiums rise even faster so that the asymmetry shrinks as female premiums rise.

Formally, to get an individualized asymmetric virginity premium, consider the thought experiment of computing an individual's virginity premium were his or her gender switched. The intuition is to match each individual to the closest individual of the opposite gender based on observables and examine the difference in virginity premiums. I first estimate the interacted model:

$$
P_{i j}=\beta_{0} F_{i j}+\beta_{1}^{\prime} \mathbf{X}_{i j} F_{i j}+\alpha^{\prime} \mathbf{X}_{i j}+\gamma_{j}+\varepsilon_{i j}
$$

I then compute for each female and each male:

$$
A V P_{i j}=\widehat{\beta_{0}}+\widehat{\beta_{1}} / \mathbf{X}_{i j}
$$

which is a proxy for the individualized asymmetric virginity premium. Appendix Table B displays the estimates as if $\mathbf{X}_{i j}$ were regional fixed effects.

Theory suggests asymmetric virginity premiums $\left(w_{f a}-w_{f p}\right)-\left(w_{m a}-w_{m p}\right)$ to be positively correlated with female virginity premiums, $\left(w_{f a}-w_{f p}\right)$, but not male virginity premiums, $\left(w_{m a}-w_{m p}\right)$. In fact, as $\left(w_{m a}-w_{m p}\right) \rightarrow 0$, then the asymmetric virginity premium may not be correlated with male virginity premiums at all. 
Table 4 estimates the OLS regression for females and for males:

$$
P_{i j}=\psi A V P_{i j}+w_{i j}
$$

relating the asymmetric virginity premium with gender-specific virginity premiums.

Columns 1 and 2 in Table 4 indicate female virginity premiums and asymmetric virginity premiums are strongly positively correlated in both China and the US. Columns 3 and 4 indicate male virginity premiums are not related to asymmetries in China and are negatively related to the asymmetries in the US. This suggests examining the impact of female virginity premiums may be similar to examining the impact of asymmetric virginity premiums.

\section{Estimating the Impact of Virginity Premiums on Gender Violence}

The theory suggests the following structural relationship:

$$
V_{i j}=\beta P_{i j}+\alpha^{\prime} \mathbf{X}_{i j}+\gamma_{j}+\varepsilon_{i j}
$$

where $V_{i j}$ represents gender violence for individual $i$ in region $j, P_{i j}$ represents the virginity premium for individual $i$ in region $j, \mathbf{X}_{i j}$ represents demographic control variables, age, education, urban, income, white, immigrant, household size, and raised with religion, and $\gamma_{j}$ is region fixed effects. The OLS relationship between virginity premiums and forced sex may be biased downwards (Table 7 Column 1) if virginity premiums are associated with views that consider forced sex to be shameful: "Women are told if you suffer molestation

or groping, you should be ashamed. Talking about it to anyone taints you for the rest of your life." (French 2003)

I exploit variation in conservatism of religious upbringing to identify the effect of virginity premiums, the idea being that the more conservative the religious upbringing, the greater the female virginity premium. The first stage regression is:

$$
P_{i j}=\pi_{0} Z_{i j}+\pi_{1}^{\prime} \mathbf{X}_{i j}+g_{j}+\eta_{i j}
$$

where $Z_{i j}$ represents the instrument, conservativeness of religious upbringing. I consider two alternative measures of religious conservativeness. One is whether the religious up- 
bringing is evangelical or not. Evangelical is defined as the Protestant denominations of Baptist, Seventh Day Adventists, Pentecostal, Amish, Church of God, Churches of Christ, and other, where other is not the mainline denominations of Lutheran, Methodist, Presbyterian, Episcopalian, Quaker and Disciplines of Christ (Evans 2004). The second measure is an index from 0 to 1 , where 1 is the fraction of charitable giving contributed to religion, the idea being that religious intensity is a function of the degree of participation in social insurance (Chen 2004a). The actual values are Mormons (0.91), Evangelical Protestant (0.82), Mainline Protestant (0.62), Catholic (0.51), Other (0.50), Jewish (0.40), and None (0.40) taken from the Center on Philanthropy Panel Study (Evans 2004).

The corresponding reduced form regression is:

$$
V_{i j}=\beta Z_{i j}+\alpha^{\prime} \mathbf{X}_{i j}+\gamma_{j}+\varepsilon_{i j}
$$

I then conduct two control experiments for traditionalism, using parental education and immigrant status to check if unobservables correlated with both religiously conservative backgrounds and with parental education increase gender violence or if unobservables correlated with both religiously conservative backgrounds and immigrant backgrounds increase gender violence.

\subsection{First Stage: Religious Background and Virginity Premiums}

Table 5 documents the relationship between religious background and female virginity premiums using the specification in equation 2. Column 1 indicates women raised in evangelical or religiously conservative backgrounds report higher virginity premiums. Interestingly, Column 2 indicates women raised in evangelical and religious conservative backgrounds are no more likely to think of teenage sex as a moral issue, suggesting there is something particular about the morality of virginity as opposed to teenage sex more generally that is a concern of evangelicals and religious conservatives. Also, perhaps interestingly, women raised in evangelical backgrounds are no less likely to have premarital sex, as indicated in Column 3. Women raised in religious conservative backgrounds are less likely to have premarital sex (this difference is driven by Mormons: 69\% of women raised in Mormon households did not have premarital sex but for evangelical backgrounds and the population more generally, $20 \%$ of women did not have premarital sex). Column 4 tests whether virginity premiums proxy for prudishness. However, women raised in religiously conservative backgrounds are somewhat more likely to think about sex. 


\subsection{Reduced Form Evidence}

Do women with higher virginity premiums suffer more gender violence? To test this, I estimate equation 3. Panel A in Table 6 indicates women raised in evangelical backgrounds are $6 \%$ more likely to have forced sex. Column 1 displays the linear probability model and Column 2 displays the marginal effects from a probit model. Panel B corroborates that women raised in religiously conservative backgrounds are again more likely to have forced sex.

\subsection{Control Experiments}

In examining the causal impact of female virginity premiums on gender violence, an important threat to identification is whether conservativeness of religious upbringing is correlated with omitted factors that increase gender violence. The data allows conducting two control experiments for traditionalism, using parental education and immigrant status to check if unobservables correlated with both religiously conservative backgrounds and with parental education increase gender violence or if unobservables correlated with both religiously conservative backgrounds and immigrant backgrounds increase gender violence.

The pattern of female virginity premiums is much less pronounced for parental education and immigrants. I estimate equation 2 for parental education in Panel $\mathrm{C}$ and immigrant status in Panel D of Table 5. Parental education is not related to female virginity premiums. Immigrant women have higher but not statistically significantly higher virginity premiums. Panel $\mathrm{C}$ of Table 6 displays the reduced form relationship, specified in equation 3. Again, the contrast is apparent. Parental education is unrelated to forced sex. Immigrant women have less but not statistically significantly less forced sex.

\subsection{SLS Estimates}

Table 7 estimates equation 1 for linear and probit specifications. Columns 2 and 3 suggest when a woman who moves from one level of virginity premium to the next, she is $25 \%$ to $34 \%$ more likely to suffer forced sex. Column 1 presents OLS and probit marginal effects estimates of equation 1 . The OLS relationship between virginity premiums and forced sex may be biased downwards if virginity premiums are associated with views that consider forced sex to be shameful: "Women are told if you suffer molestation or groping, you should be ashamed. Talking about it to anyone taints you for the rest of your life." (French 2003) 


\subsection{Male Responses}

The OLS relationship between virginity premiums and forced sex may be biased downwards for women if shame is associated with abuse and this shame is greater for women with higher virginity premiums. But the OLS relationship for males might not be biased downwards.

Table 8 estimates the OLS regression for males:

$$
V_{i j}=\psi A V P_{i j}+w_{i j}
$$

where $A V P_{i j}$ is computed as in section 4.4 and $V_{i j}$ refers to male reports of forcing women to do something sexual that she did not want to do and whether they have ever paid a woman to have sex.

Column 1 indicates the asymmetry is positively correlated with forcing women and Column 2 indicates the asymmetry is positively correlated with paying women.

\section{Conclusion}

This paper builds and tests a model of marriage as an incomplete contract that arises from asymmetric virginity premiums, the inequality between men and women's ex ante and ex post marriage market opportunities. The model has the predictions men may seek to lower women's ex ante "market wages" in order to induce entry into joint production. Inefficient or abusive marriages are less likely to separate.

I find suggestive evidence asymmetric virginity premiums persist over economic development and that they may be reduced by education but not always. The asymmetry is highly correlated with female but not male virginity premiums. Women raised in conservative religious backgrounds have higher virginity premiums and more forced sex but this is not due to parental education or immigrant traditionalism. Asymmetric virginity premiums are positively correlated with men forcing sex on women and paying women for sex.

To the extent governments, international organizations, and NGOs are concerned about gender violence, the results suggest lowering female or raising male virginity premiums would be Pareto improving. Subsidizing prices that women pay doctors to appear virgin before marriage, or informing women that they are commonly available, would in equilibrium reduce the asymmetric virginity premium, but would it reduce $80 \%$ of gender violence (Kandela 1996)? The US has the highest incidence of rape in the western industrial world, 
which may be related to it also having the highest virginity premiums: 2.4 million people in the US have signed "virginity pledges" since 1993 (Bearman and Bruckner 2001); are these pledges, and sex-education more generally, alleviating or exacerbating the asymmetry?

Social commentators and casual observation suggests inverse premiums exist among some age groups and regions in the Western world today (Denizet-Lewis 2004). The model's predictions would be reversed in this case $\left(w_{f p}-w_{f a}>w_{m p}-w_{m a}\right.$, typically, when $\left.w_{f p}>w_{f a}\right)$ : women have the incentive to fete and lower men's ex ante market wages. Same-sex vs. mixed-sex marriages can also be examined by this model. To the extent same-sex marriages lack asymmetric virginity premiums, they would be more efficient than mixed-sex marriages.

Constructing policy interventions to reduce asymmetric virginity premiums is limited only by the imagination. Traditional Islam in central Java prohibits men from wearing wedding rings but require women to do so. This clearly exacerbates the asymmetry of market opportunities even within marriage. Could randomly distributing wedding rings induce a separating equilibrium where men of different types choose whether or not to wear the wedding ring, and women observe this, which in equilibrium reduces gender violence and sexually transmitted diseases?

Certain beliefs may be a channel through which gender violence arises, indicating that in the mechanism design of optimal beliefs, gender differences between ex ante and ex post marriage market opportunities should be reduced. When one considers that in many societies female rape victims are blamed or outcasted by their own families, female mutilation, forced marriages, stoning, and witch trials from Salem to Kenya, it is easy to consider band-aid solutions that fall off without understanding the underlying cause of the phenomena. This paper shows how asymmetric virginity premiums may drive many of the visible manifestations of female appropriability across time and space, suggesting that in terms of policy, changing these asymmetries may mitigate a plethora of rights violations.

\section{$7 \quad$ Data Appendix}

The empirical analysis draws from two sources, the Chinese Health and Family Life Survey (CHFLS) and the National Health and Social Life Survey (NHSLS), both collected by the NORC. CHFLS is a nationally representative survey conducted between 1999 and 2000 of the adult population in China, ages 20 to 64, with the exception of Tibet and Hong Kong. Interviewers were the same gender as the respondent. For the sake of privacy, 
interviews took place away from the respondent's home. Portions of the interview were completely computerized to maximize privacy. The sample size is 3,821 . The NHSLS is a nationally representative survey of the US adult population in 1992 with a sample size of 3,432 . Portions of the interview were answered and submitted in a privacy envelope away from the interviewer to maximize privacy.

The female measure of gender violence refers to the question, "This section relates to what you have done sexually with a man since you reached puberty (that is since you were about 13 years old). Have you ever been forced by a man to do something that you did not want to do?" The question is coded as $1 / 0$. I show both linear probability and probit marginal effects specifications. Using self-reported forced sex addresses some of the concerns of human rights activists that pain may be culturally specific and social scientists ought not to define what is "forced" for others. A social planner would also optimize self-reported utility.

The male measure of gender violence refers to the question, "This section relates to what you have done sexually with a woman since you reached puberty (that is since you were about 13 years old). Have you ever forced a woman to do something that she did not want to do?" The question is coded as $1 / 0$. I also examine the question, "Have you ever paid a woman to have sex?"

In CHFLS, the measure of virginity premiums refers to the question, "Nowadays in our society, some couples have sex when they are dating, and they eventually get married. Is this a moral issue? What is your opinion?" The question is coded as $1 / 2 / 3 / 4$, with higher values indicating increasing moral value placed on virginity. As a comparison question, I also proxy for traditionalism with, "Some say that a wife should be responsible for the family and domestic tasks while a husband should focus on career and matters outside the household. Do you agree?" The question is also coded as $1 / 2 / 3 / 4$. The comparison highlights a premium placed on virginity not just traditional gender roles in general.

In NHSLS, the measure of virginity premiums refers to the question, "There's been a lot of discussion about the way morals and attitudes about sex are changing in this country. If a man and a woman have sex relations before marriage, do you think it is always wrong, almost always wrong, wrong only sometimes, or not wrong at all?" The question is coded as $1 / 2 / 3 / 4$, with higher values indicating increasing moral value placed on virginity. As comparison question, I consider the question, "What if they are in their teens, say 14-16 years old? In that case, do you think sex relations before marriage are always wrong, almost always wrong, wrong only sometimes, or not wrong at all?" The question is also 
coded as $1 / 2 / 3 / 4$. This comparison highlights a particular premium placed on virginity as opposed to teenage sexual activity.

I consider two alternative measures of religious conservativeness of upbringing. One is whether the religious upbringing is evangelical or not. Evangelical is defined as the Protestant denominations of Baptist, Seventh Day Adventists, Pentecostal, Amish, Church of God, Churches of Christ, Pentecostals, and other, where other is not the mainline denominations of Lutheran, Methodist, Presbyterian, Episcopalian, Quaker and Disciplines of Christ (Evans 2004). The second measure is an index from 0 to 1, where 1 is the fraction of charitable giving contributed to religion. The actual values are Mormons (0.91), Evangelical Protestant (0.82), Mainline Protestant (0.62), Catholic (0.51), Other (0.50), Jewish (0.40), and None (0.40) taken from the Center on Philanthropy Panel Study (Evans 2004).

Demographic control variables in CHFLS are age, education, urban, working, income, living at home, household size, and interview site fixed effects. Education ranges from 1 (never attended school) through 6 (attended university or graduate school). Urban is a dummy for whether the individual lived in a rural village or rural town at the age of 14 . Working is a dummy for whether the individual currently has a full-time job or is working on a farm. Income is the monthly personal income for the past 12 months. Living at home is a dummy for whether the individual is living at a parent's or child's or in-law's or own home. There are 70 interview sites reflecting the sampling method.

Demographic control variables in NHSLS are age, education, urban, income, white, immigrant, household size, raised with religion, and region fixed effects. Education ranges from 1 ( 8 th grade or less is the highest schooling completed) to 8 (advanced degree). The placebo instrument, parental education, is the average education of the mother and father. Urban is a dummy for current residence. White, immigrant, and raised with religion are dummy variables. There are 9 regions: New England, Mid-Atlantic, South Atlantic, East South Central, West South Central, East North Central, West North Central, Mountain, and Pacific.

I use the entire sample of 3,821 households for the China portion of the analysis and the entire sample of 3,432 households for the US portion of the analysis. Appendix Table A presents some descriptive statistics. 


\section{References}

Aizer, Anna and Pedra Bo (2004) "Love, Hate and Murder: Commitment Devices in Violent Relationships," Brown University mimeo.

Altman, Lawrence. (2004) "Study Finds that Teenage Virginity Pledges Are Rarely Kept," New York Times, March 10.

Aries, P. and Georges Duby. (1992) A History of Private Life, Vol 1-5, Harvard University Press.

Assessoria Especial Das Delegacias De Defesa Da Mulher Do Estado De São Paulo, General Statistics, 1989.

Bearman, Peter S. and Hannah Bruckner (2001) "Promising the Future: Virginity Pledges and First Intercourse," American Journal of Sociology, 106(4), 859-912.

Becker, Gary. (1991) A Treatise on the Family, Harvard University Press.

Bedard, K. and O. Deschenes. 2003. "Sex Preferences, Marital Dissolution, and the Economic Status of Women." Unpublished working paper 6-03, University of CaliforniaSanta Barbara, Santa Barbara.

Bernheim, Douglas, Carman, K., Kotlikoff, L J, and Novarro, N. (2004) "How Do Widowhood and Divorce Affect Economic-Well Being? Evidence from the Health and Retirement Survey," Stanford University mimeo.

Bernstein, Nina (2004) "More Teenagers are Striving for Restraint," New York Times, March 7.

Bloch, Francis and Vijayendra Rao, "Terror as Bargaining Instrument: A Case-Study of Dowry Violence in Rural India," American Economic Review, September 2002.

Botticini, M. and A. Siow, (2002) "Why Dowries", American Economic Review.

Bowlus, Audra J. and Shannon N. Seitz (2002), "Domestic Violence, Employment and Divorce," Queen's University mimeo.

Caballero, R. and M. Hammour (1998), "The Macroeconomics of Specificity," Journal of Political Economy 106(4), 724-767.

Chen, Daniel L. (2004), "Club Goods and Group Identity: Evidence from Islamic Resurgence During the Indonesian Financial Crisis," University of Chicago mimeo.

Chen, Daniel L. (2004), "Does Religious Intensity Cause Social Violence?" University of Chicago mimeo.

Chiappori, Pierre A. and Yoram Weiss (2003) "Marriage Contracts and Divorce: an Equilibrium Analysis," University of Chicago mimeo. 
Choi, Sue Yeon (1998), "Restoring Virginity," Berkeley Medical Journal.

Connolly, Ceci. "Texas Teaches Abstinence, With Mixed Grades," Washington Post.

Constable, Pamela (2003) "Beset Afghan Girls' Schools," Washington Post, September

8.

Crittenden, Ann (2001) The Price of Motherhood: Why the Most Important Job in the World is Still the Metropolitan Books.

Denizet-Lewis, Benoit (2004) "Friends, Friends With Benefits and the Benefits of the Local Mall," New York Times, May 30.

Drumm, Rene D., M. Popescu, J. Wrenn, and D. McBride (2004) "Abuse Issues in a Conservative Christian Denomination: How Similar are Congregants in Diverse Regions?" Andrews University mimeo.

Duby, Georges and Michelle Perrot eds. (1994) A History of Women, Vol 1-5, Harvard University Press.

Duflo, Esther and Chris Udry (2003) "Intrahousehold Resource Allocation in Cote D'Ivoire: Social Norms, Separate Accounts and Consumption Choices," Yale University Economic Growth Center Discussion Paper No. 857.

Edlund, Lena, (1999) "Son preference, sex ratios, and marriage patterns", Journal of Political Economy.

Epstein, H. "The Fidelity Fix" New York Times, June 13, 2004

Epstein, Louis M. (1973) The Jewish People: The Jewish Marriage Contract. Arno Press, New York.

Evans, Thomas. (2004) "Religion and Charitable Giving," University of Illinois mimeo.

Field, Erica (2004) "The Consequences of Early Marriage in Bangladesh," Harvard University mimeo.

Filkins, Dexter (2003) "'Honor Killings' Defy Turkish Efforts to End Them," New York Times, July 13.

Fisman, Raymond, Sheena Iyengar, Emir Kamenica, and Itamar Simonson, (2004) "Searching for a Mate: Theory and Experimental Evidence," Columbia University mimeo.

French, Howard W. (2003) "Victims Say Japan Ignores Sex Crimes Committed by Teachers," New York Times.

Glaeser, Edward L., and Bruce I. Sacerdote, (2008) "Education and religion." Journal of Human Capital 2.2: 188-215.

Goody, Jack ed. (1973) Character of Kinship, Cambridge University Press. 
Goody, Jack (1983) The Development of Family and Marriage in Europe, Cambridge University Press.

Goody, Jack (1976) Production and Reproduction, Cambridge University Press.

Heise, Lori, Jacqueline Pitanguy and Adrienne Germain (1994) Violence Against Women: The Hidden Hea The World Bank.

Holden, Karen and Smock, Pamela J. (1991) "The Economic Costs of Marital Dissolution: Why do Women Bear a Disproportionate Cost?" Annual Review of Sociology, 1991, 17: 51-78.

Hotchkiss, J. and M. Melinda Pitts (2003) "At What Level of Labor-Market Intermittency are Women Penalized?" American Economic Review.

Human Rights Watch, "The Human Rights Watch Global Report on Women's Human Rights"

Kahn, Joseph and J. Yardley (2004) "Amid China's Boom, No Helping Hand for Young Qingming," New York Times, August 1.

Kandela, Peter (1996) "Egypt's Trade in Hymen Repair," Lancet, Vol 347, No 9015.

Kew, Melissa (2004) "Unwanted Sexual Activity Among Married Women in Urban China," University of Chicago mimeo.

Kristof, Nicholas D. (2004) "Beaten Afghan Brides," New York Times, October 6.

Kristof, Nicholas D. (2004) "Sentenced to be Raped," New York Times, September 29.

Lakhani, Arif (2004) "The Price of Honor," South Asian Journal, Harvard University.

Laumann, Edward O., John H. Gagnon, Robert T. Michael, and Stuart Michaels (1994).

The Social organization of sexuality in the United States. Chicago: University of Chicago Press.

Laumann, Edward O., Steven Ellingson, Jenna Mahay, Anthony Paik, and Yoosik Youm. (2004) The Sexual Organization of the City. University of Chicago Press.

Laumann, Edward O. and Robert T. Michael. (2000) Sex, Love and Health. Private Choices and Public Pc Chicago: University of Chicago Press.

Lee, James Z. and Feng Wang (2000) One Quarter of Humanity: Malthusian Mythology and Chinese Reali Harvard University Press.

Michael, Robert T., John H. Gagnon, Edward O. Laumann, and Gina Kolata. (1995) Sex in America: A definitive survey. Boston: Little, Brown.

Nicolo, Antonio and Piero Tedeschi (2003) "Incomplete Contracts as Strategic Device: Applications to Nuptial and Partnership Agreements," U of Padua mimeo.

Nussbaum, Martha (1996) "Double Moral Standards?" Boston Review. 
Onishi, Norimitsu (2003) "Divorce in South Korea: Striking a New Attitude," New York Times, September 21.

Oriang, Lucy (2003) "It's a Craze We're Going Through," Daily Nation on the Web, The East African, November 21.

Pan, Philip. "Forbidden Love Challenges Rules in China," Washington Post Foreign Service

Pezzini, Slvia (2003), "The Effect of Women's Rights on Women's Welfare: Evidence from a Natural Experiment," LSE mimeo.

Posner, Richard (1992), Sex and Reason, Harvard University Press.

Rangel, Marcos (2004) "Alimony Rights and Intra-Household Allocation of Resources: Evidence from Brazil," UCLA mimeo.

Rasul, Imran (2004) "Household Bargaining over Fertility: Theory and Evidence from Malaysia," University of Chicago mimeo.

Rhode, Deborah L. (1999) Speaking of Sex: The Denial of Gender Inequality. Harvard University Press.

Rubinger, Maria, et. al., Crimes Contra A Mulher, Introduction.

Scheffler, Mark (2004) "So, How's Your Sex Life?" Chicago Tribune Magazine, November 14, 2004.

Seattle Times, http://seattletimes.nwsource.com/news/nation-world/html98/honr06_20000706.html.

Segal, Ilya (1999) "Complexity and Renegotiation: A Foundation for Incomplete Contracts," Review of Economic Studies, 66, 57-82.

Silverman, Jay (2001) "Dating Violence Against Adolescent Girls and Associated Substance Use, Unhealthy Weight Control, Sexual Risk Behavior, Pregnancy, and Suicidality," Journal of the American Medical Association.

Stevenson, Betsey and J. Wolfers (2003) "Til Death Do Us Part: The Effects of Divorce Laws on Suicide, Domestic Violence and Intimate Homicide," NBER Working Paper 10175.

Waite, Linda (2000), The Case for Marriage, Doubleday. 


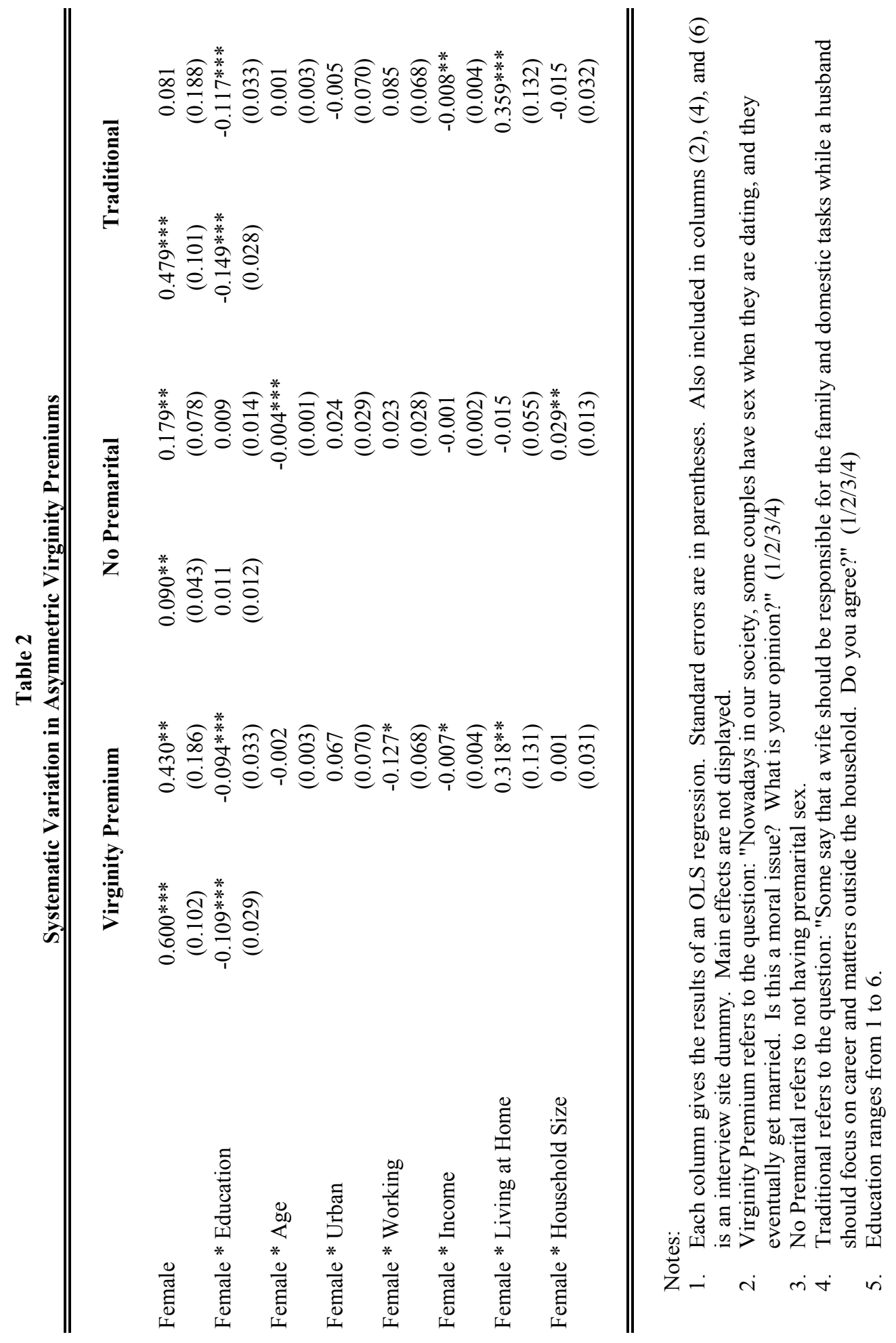




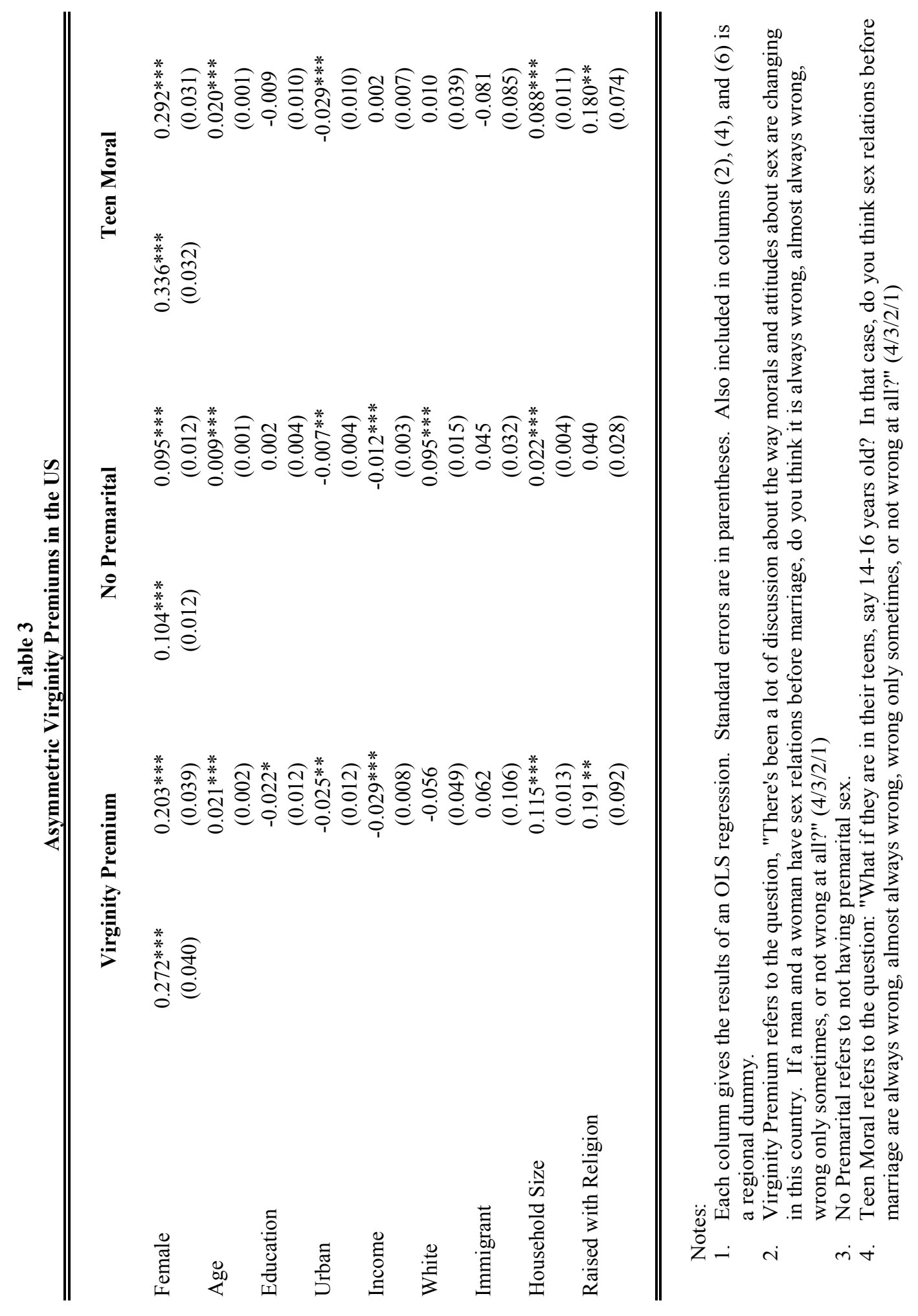




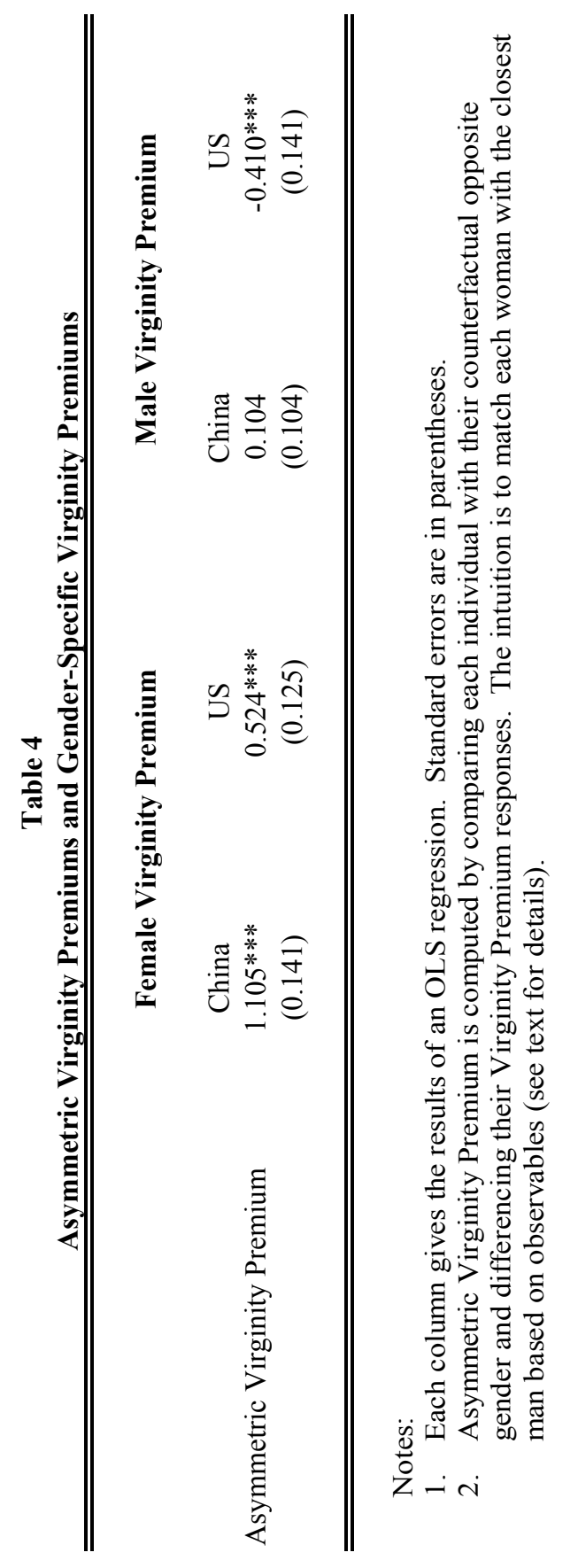




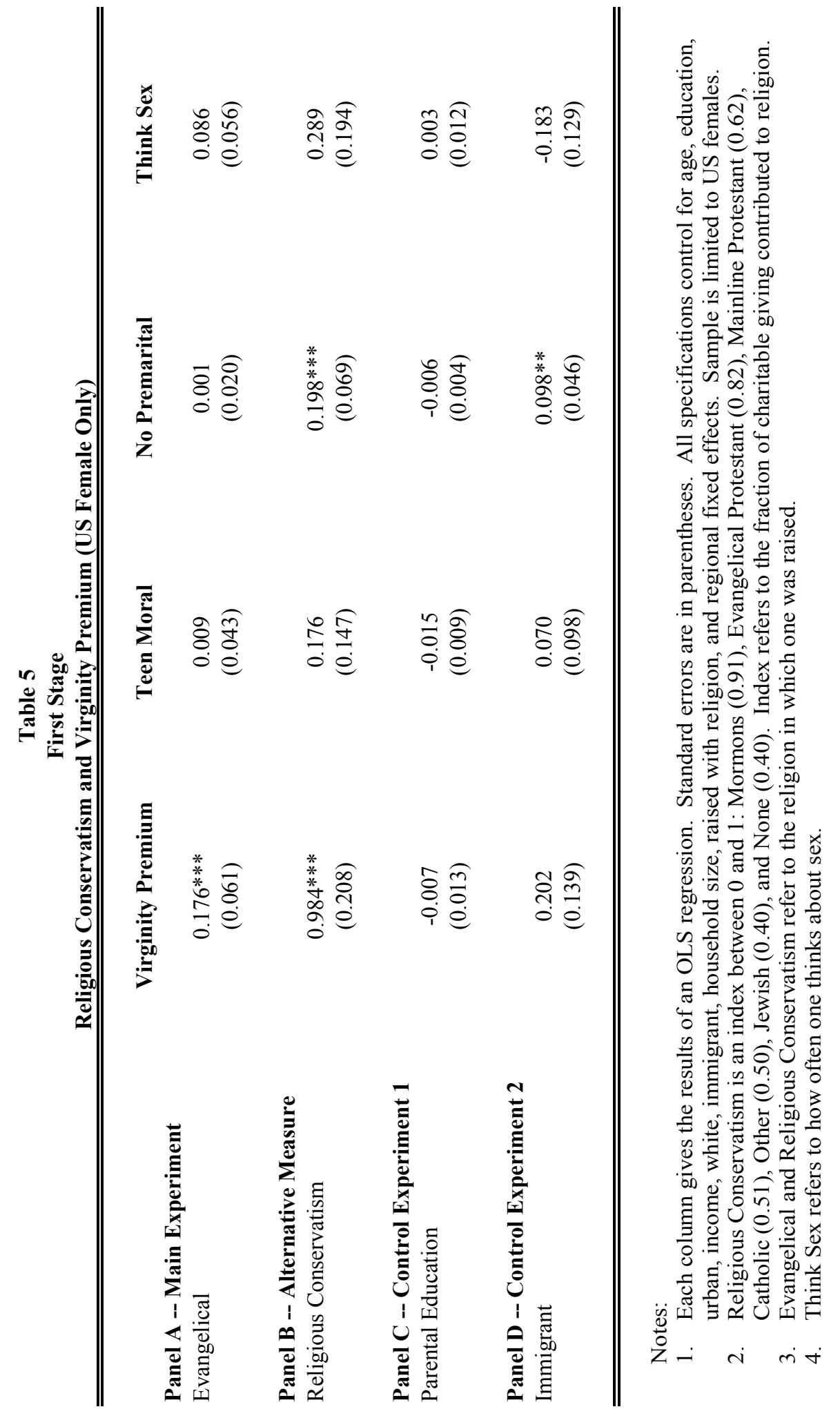




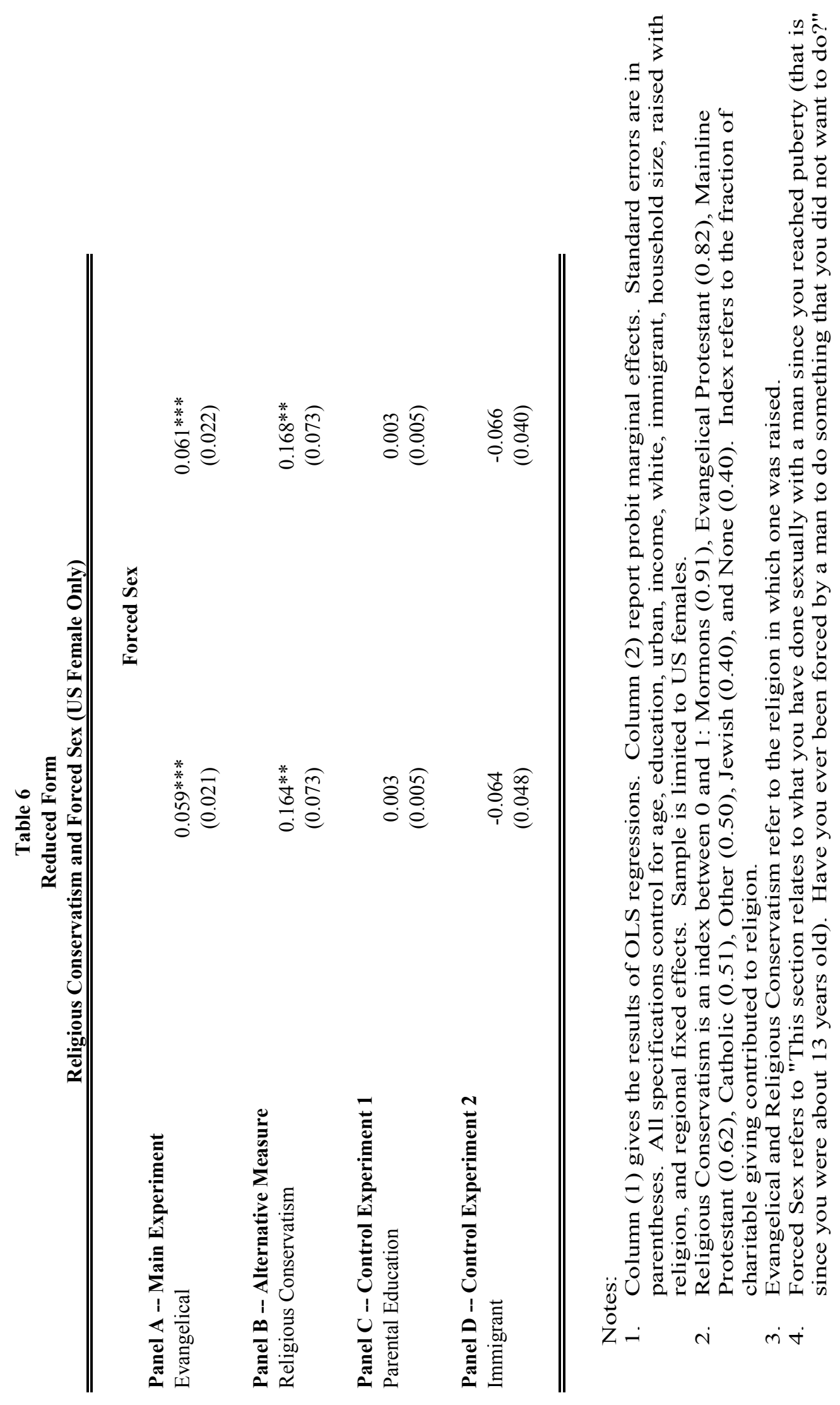




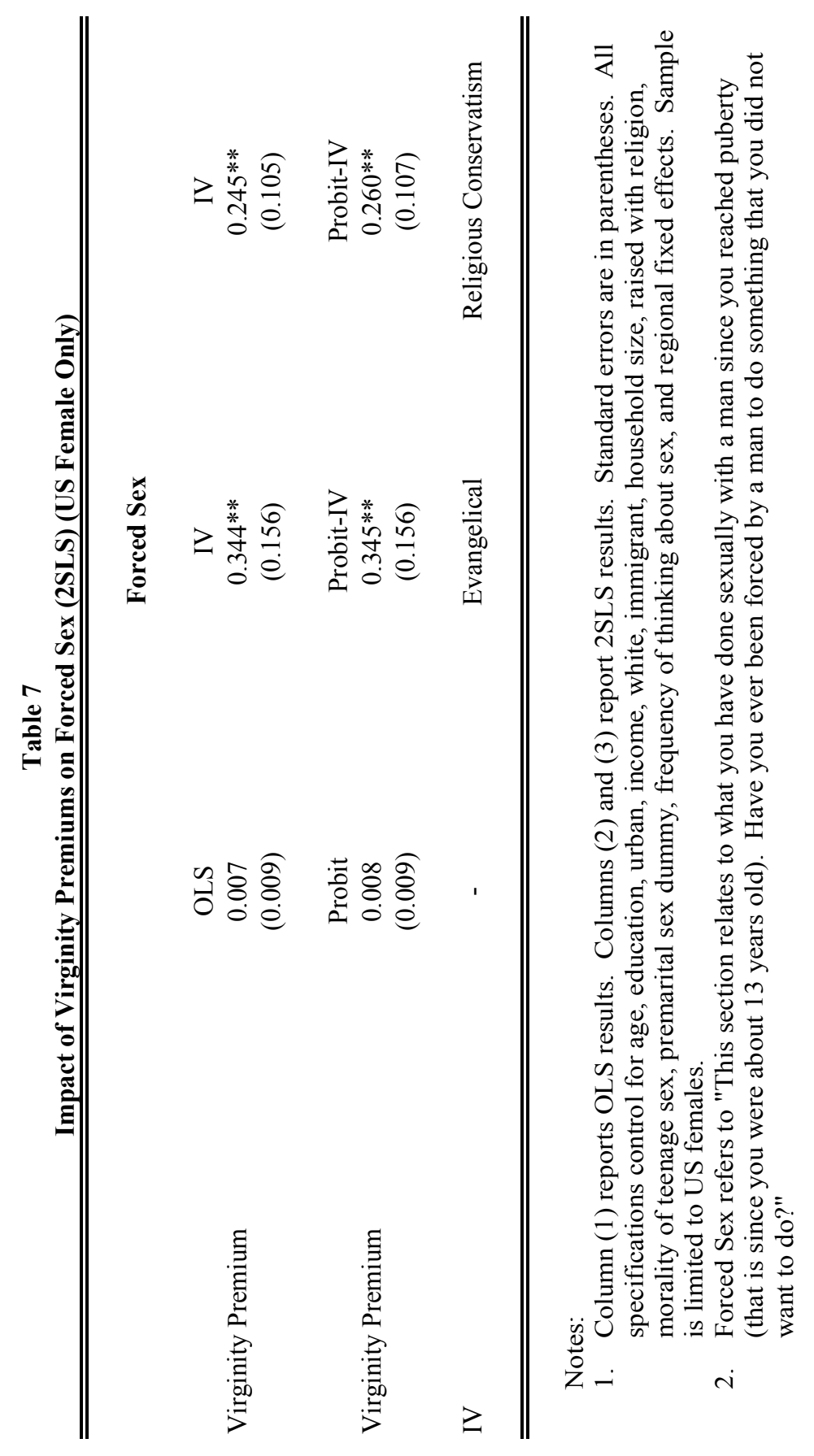




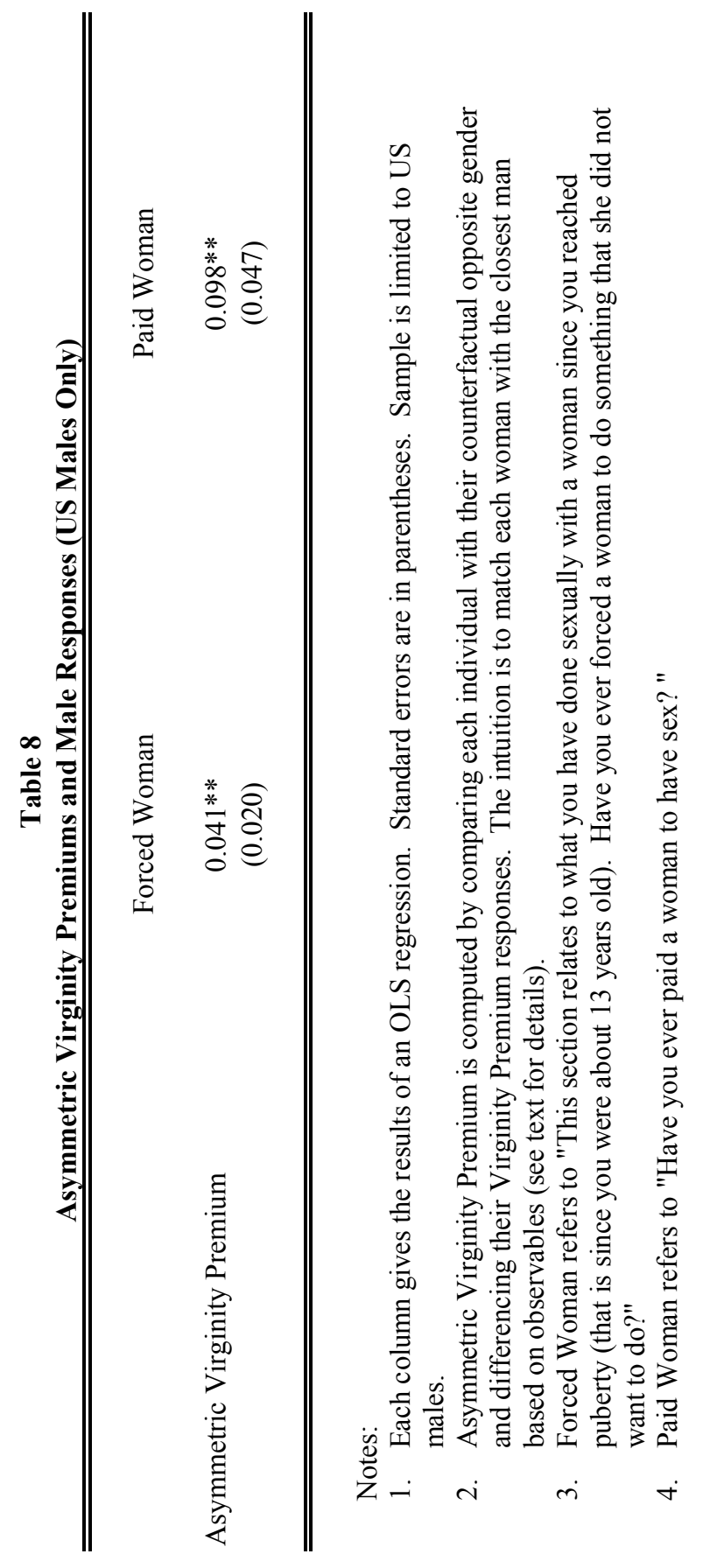




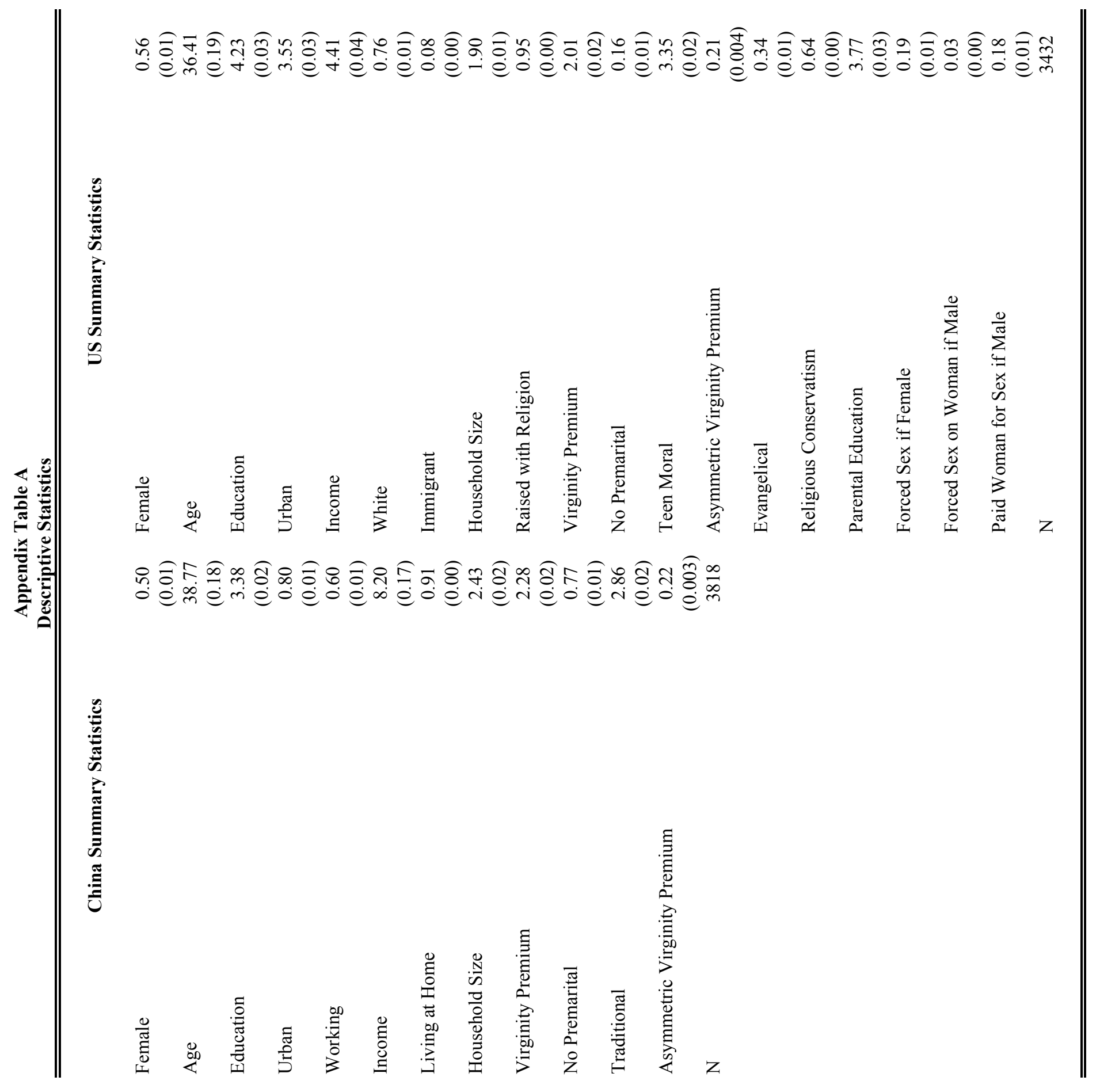




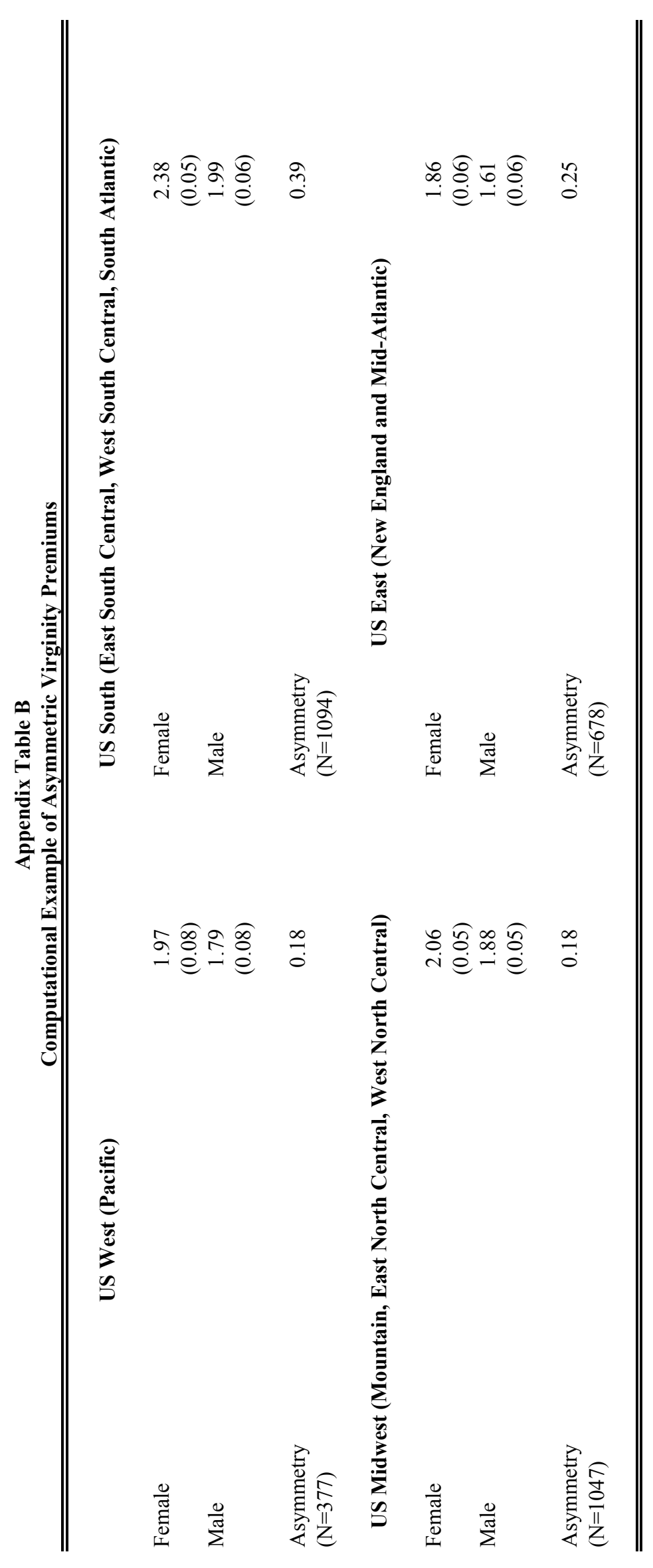

